\title{
Methodological aspects of modeling the fuel and energy complex in the context of energy security
}

\author{
Victoria Piskunova ${ }^{1,2, *}$ \\ ${ }^{1}$ Melentiev Energy Systems Institute of the Siberian Branch of the Russian Academy of Sciences, 130 Lermontov Str., \\ Irkutsk, Russian Federation \\ ${ }^{2}$ Irkutsk National Research Technical University, 83 Lermontov Str., Irkutsk, Russian Federation
}

\begin{abstract}
One of the most important goals of the energy industry is to ensure a shortage-free and reliable energy supply to consumers. To achieve this goal, it is necessary to assess the level of energy security of the fuel and energy complex (FEC) of the country. For these purposes, it is proposed to form a model of the energy system that would take into account the peculiarities of all process flows that take place in it. For this purpose, we conducted a review of Russian and foreign studies in the field of modeling of the FEC in the course of the work. The main result presented in the article is a methodology for the building of a unified model of the fuel and energy complex to assess the level of energy security.
\end{abstract}

\section{Introduction}

Ensuring the reliability of energy systems and energy security are important components of economic development. The article deals with the modeling of energy systems in the study of energy security. The main issues under consideration are the following:

- Analysis of existing mathematical models of the fuel and energy complex that have been designed to analyze the issues of ensuring energy security and developed at the Melentiev ESI, SB RAS. We analyze the strengths and weaknesses of the models and lay the foundation to form a methodology for modeling the fuel and energy complex;

- We present a methodology for forming a multi-node model with a wide variety of primary energy resources, including renewable energy and water systems, as well as secondary energy resources, including cold energy.

- We state the basic requirements for the joint modeling of energy systems of different types and their interaction with each other;

- We present a model of the electric power system and outline the approaches to the mathematical treatment of each element.

In what follows, the article is further organized as outlined below. Section 2 provides an overview of the research aimed at modeling the interconnected operation of energy systems of various types. Section 3 presents an analysis of the mathematical models of the fuel and energy complex as developed at the Melentiev ESI, SB RAS. The mathematical model of the electric power system and a description of its elements are presented in Section 4.
Finally, the concluding section 5 presents the results of the work done.

\section{Review}

Most foreign studies lack "the fuel and energy complex" concept. Instead, the authors consider diverse variations of integrated energy systems (IES). The IES converts conventional and renewable energy, such as solar and wind, into cold energy, heat, and electricity to improve the overall efficiency of energy use and increase the flexibility and economic performance of energy supply [1]. It is worth noting that the FEC or integrated energy systems can be considered at different levels of scaling. Thus, the object of the study may be the FEC of a small settlement, as well as the FEC of the country or interstate unions. Certain mathematical models and equivalence methods should be used for each level of scalability. Also, the set of the problems solved by modeling the FEC can vary, among the main arrays of problems to be solved, we can traditionally distinguish between the problems of managing the operation and development.

Articles [2-20] present studies aimed at modeling integrated energy systems and optimizing their energy flows. Let us look at some of the studies in more detail. In [2], the authors modeled a multi-energy microgrid in order to study day-ahead dispatching. The equipment presented in the model is divided into three categories: generation units based on renewable energy sources (photovoltaic cells), linking equipment of the energy hub (voltage transformer, CHPP, and gas boiler), and energy storage devices. All elements are described by non-linear equations.

* Corresponding author: vitapiskunova98@gmail.com 
In the study [4] an energy hub, whose generation is based entirely on renewable energy, is modeled to convert biomass, hydro-, wind, and solar energy into electricity, biogas, heating, and cooling flows. The model includes redundant connections between energy sources for operational flexibility.

In [6], the author model a smart building with its own energy production (gas turbine). The power grid and the gas trunk line are modeled as external energy supply. The study describes the possibility of interchangeability of different energy resources. The mathematical treatment is presented as a system of linear equations.

In [7], the authors model the interaction between microgrids with multiple carriers and energy storage facilities as a complex energy hub that takes into account different electrical, heating, and cooling resources. The model provides resource sharing to arrange redundancy.

The article [10] presents a multi-energy system with combined electricity and natural gas supply infrastructure. The resulting mixed-integer linear representation models the electrical and gas equilibrium by hour during the month. The model aims to determine the optimal supply system based on fault tolerance criteria.

To determine the optimal placement of energy storage devices, in the study [13], the authors built an integrated model of the energy system, including an electric boiler for heat storage, an ice storage device, a storage battery, and a P2G system. The integrated energy system includes four forms of energy: cooling, heating, electricity, and gas and has the characteristics of different types of load and power supply equipment.

In [16], a grid-connected IES consisting of energy supply equipment, energy storage equipment, and three types of loads is modeled. The gas boiler, CHPP, and renewable energy are represented as generation equipment.

Study [19] demonstrates the use of dynamic modeling to simulate and evaluate the stability of an integrated energy system that includes three energy carriers: electricity, heat, and gas. In the power grid, the authors implemented three aggregated consumers with standard load profiles: industry, agriculture, and households. In the model, the load responds linearly to frequency. The demand for electricity is covered by wind turbines, photovoltaics, a biomass power plant, an incineration plant, and a CCGT unit. The authors also implemented an electricity storage device to absorb possible excess electricity and avoid reducing the use of renewable energy sources. Transmission line models are quasi-stationary and allow the calculation of voltage drops and power losses. The heating section consists of three parts: two residential areas, which are supplied with heat by gas boilers, and one residential area, where households are connected to the district heating network supplied by the CCGT unit. The gas section consists of eight pipelines forming a loop, which ensures redundancy. The network serves three gas consumers: an industrial consumer and two residential areas that burn gas in boilers for heating. To assess the stability of the system, the authors model a 14-hour long emergency at one of the sections of the loop gas pipeline. This period of gas outages is chosen so as to match the Baumgarten explosion in December 2017.
The analysis revealed that most of the studies considered the individual nodes of the energy system and mentioned the possibility of their interaction with each other. According to the statistical data compiled, the more equipment is considered in the study, the fewer territorial clusters are modeled. Of all the reviewed studies, only the last one appears to be of interest in terms of its more indepth study in the context of the work planned due to the fact that it presents a multi-node model with a large amount of equipment and energy carriers.

\section{Mathematical models of the FEC designed for energy security research and developed at the Melentiev ESI, SB RAS}

Research into energy security has been carried out at the Melentiev Energy Systems Institute SB RAS for a long period of time with dedicated mathematical models of energy systems and the FEC as a whole being developed [21-24]. Models have been developed since 1980 and there are currently three main modifications, which will be described in detail in this section. These models that include "Nadezhnost' TEK" (Reliability of the fuel and energy complex), "Rezerv" (Redundancy), and "REKS" (Development of the fuel and energy complex with energy security factored in) are based on a system of linear balance equations with a given constraint matrix. Each subsequent model was a revised and expanded version of the previous model, however, the basis of the model and the objective function remained similar. It is worth noting that all the models are focused on the analysis of large interconnections and were used to analyze the FEC of the USSR and Russia.

\subsection{The "Nadezhnost' TEK" model}

The main objectives of the economic and mathematical model of the analysis and provision of the reliability of energy sector operation under large-scale disturbances ("Nadezhnost' TEK") were the analysis and assessment of the consequences of large-scale disturbances affecting the main cross-industry and cross-regional links within the fuel and energy complex of the country. Based on the analysis, one calculated the most rational way to compensate for these perturbations with interchangeable fuels and redistribution of energy flows. Solutions were worked out in advance for a period ranging from one year to a quarter of the year. The calculation time was changed by scaling the variables and introducing adjustment coefficients into the constraint system.

When developing the model, a number of simplifications were adopted, allowing for the minimum level of detail necessary to account for the two main systemically important factors: interchangeability of fuel and energy resources and territorial and transport links. Such simplifications may include the lack of consideration of fuel transportation time, inaccuracies in the representation of technological relationships, the lack of consideration of the power balance, etc. Another 
significant assumption is that the entire fuel and energy system was, in terms of its territory, divided into large economic areas, within which all production and consumption were represented in an aggregated fashion. The above factors impose significant limitations on the scope of possible applications of the model.

The model includes the following subsystems: gas, oil, coal, and electricity. All other types of primary fuel and secondary energy resources were considered in an aggregate manner (e.g., heat and nuclear fuel production). For each type of energy resource, balance equations were formed, including the aggregate values of production and consumption within the area and the supply of energy resources from another area (to another area).

In the "Nadezhnost' TEK" model, all consumers were divided into three categories: critical (I), other (II), and exports-oriented (III). Ensuring the supply of light petroleum products was a priority, so they were classified as belonging to the first category. In addition, for the first category (as well as for the second one), the volume of electricity and boiler and furnace fuel consumption (heating oil, coal, and gas) were considered. Export products (third category) included coal, gas, and crude oil. To take into account the scale of priorities depending on the category of consumers, a system of penalty coefficients for energy shortages was introduced.

The objective function of the model was defined as the problem of minimizing the shortage of energy resources and the cost of FEC operation, with the first component being to a large extent a higher priority. This is explained by the fact that the specific damages from fuel and energy shortages are an order of magnitude higher than the specific costs of production of energy resources.

\subsection{The "Rezerv" model}

The model of making control decisions under large-scale disturbances in the fuel supply system ("Rezerv") is a revised and expanded version of the "Nadezhnost' TEK" model. The model is divided into two generations: "Rezerv 1" and "Rezerv 2".

\subsection{1 "Rezerv 1"}

In the "Rezerv 1" model, a new subsystem was introduced: the thermal energy subsystem. It includes two components: thermal energy received at centralized and decentralized boiler houses, and thermal energy received at CHPPs. With the implementation of this subsystem, the way the modeling of thermal plants is performed has changed. To account for the heating load, two extreme modes of CHPP operation are adopted: condensing and cogeneration modes. Taking into account the simplifications, it is assumed that during the year, these modes are descriptive of the summer and winter seasons, respectively, since the power plant cannot instantly switch over the mode of operation.

The territorial division of the model also underwent changes due to the disaggregation of economic areas. This change is due to the need to take into account the peculiarities of the territorial organization of managing the FEC.

In the petroleum product subsystem, the qualitative composition of oil was detailed and individual types of oil were distinguished, and the ability to control the modes of operation of refineries was added.

The overall architecture of the model changed due to the introduction of a new type of consumer: end-of-period inventory. The introduction of this element was necessary to account for the effect of decisions made for the previous period on the current period. Thus, the inventory at the end of the $\mathrm{i}$-th period is the inventory at the beginning of $(\mathrm{i}+1)$ th period.

In connection with the above item, the objective function was also changed. A new summand was introduced into it, which characterizes the degree of meeting the demand for energy resources at the end of the period in question.

\subsection{2 "Rezerv 2"}

In the "Rezerv 2" model, which is the next generation of the "Rezerv 1" model, its authors introduced several significant changes into the overall architecture. Autonomous republics and krais were distinguished as separate economic areas which can be explained by a number of domestic changes. In addition, the calculation period of the energy sector modeling was changed. Previously, in the "Nadezhnost' TEK" and "Rezerv 1" models, it was scaled from a year to a quarter of the year; in the "Rezerv 2" model, the upper limit was reduced to a quarter of the year.

\subsection{The REKS (Development of the fuel and energy complex of the country with energy security factored in) model}

The model to optimize the development of the fuel and energy complex of the country with energy security factored in ("REKS") began to be developed simultaneously with the "Rezerv 2" model, and to date, its modification with minor changes remains the last generation of a number of models.

In terms of the territory covered, the model is represented by eight economic areas, which were defined on the basis of the existing federal districts of the country.

The CHPP modeling method was also changed. In the model under consideration, the relationship between heat and electricity is taken into account by means of an estimated coefficient derived based on the analysis of statistical data on energy production at CHPPs.

The physical meaning of the coefficient is to capture the dependency of heat production per $1 \mathrm{MW}$ of electric power. Condensing and heating modes of operation are not treated separately. 
Table 1. Summary table of FEC models

\begin{tabular}{|c|c|c|c|c|}
\hline Model name & Balance equations & Objective function & Territory & $\begin{array}{c}\text { Calculation } \\
\text { time }\end{array}$ \\
\hline $\begin{array}{l}\text { "Nadezhnost' } \\
\text { TEK" } \\
\text { (Reliability of } \\
\text { the FEC) } \\
\text { 1980-1985 } \\
\end{array}$ & $\begin{array}{c}{[\text { Production }]+[\text { reserve }} \\
\text { recovery }]+[\text { input into the } \\
\text { area }]-[\text { Output from the area }]- \\
{[\text { Consumption }] \geq 0}\end{array}$ & $\begin{array}{l}\text { Minimizing shortage } \\
\text { and operating costs. }\end{array}$ & $\begin{array}{l}19 \text { economic areas } \\
\text { of the USSR }\end{array}$ & Year \\
\hline $\begin{array}{c}\text { "Rezerv 1" } \\
\text { (Redundancy 1) } \\
1985-1990 \\
\end{array}$ & \multirow{2}{*}{$\begin{array}{l}\text { [Inventories at the beginning } \\
\text { of the period] }+[\text { production] }+ \\
{[\text { input into the area] - [output }} \\
\text { from the area] - [consumption] } \\
-[\text { Inventories at the end of the } \\
\text { period }] \geq 0\end{array}$} & \multirow[b]{2}{*}{$\begin{array}{l}\text { Minimizing shortages, } \\
\text { operating costs, and the } \\
\text { cost of storing } \\
\text { inventory. }\end{array}$} & $\begin{array}{c}27 \text { economic areas } \\
\text { of Russia }\end{array}$ & Year \\
\hline $\begin{array}{c}\text { "Rezerv 2" } \\
\text { (Redundancy 2) } \\
1985-1990\end{array}$ & & & $\begin{array}{l}35 \text { economic areas } \\
\text { and autonomous } \\
\text { federal subjects of } \\
\text { the Russian } \\
\text { Federation }\end{array}$ & Quarter \\
\hline $\begin{array}{l}\text { "REKS" } \\
\text { (Development } \\
\text { of the FEC of } \\
\text { the country with } \\
\text { energy security } \\
\text { factored in) } \\
1990-2021\end{array}$ & $\begin{array}{c}\text { [Production] }+ \text { [reserve } \\
\text { extraction] }+[\text { new capacity } \\
\text { additions] }+ \text { [input into the } \\
\text { area] - [output from the area] - } \\
\text { [consumption] - } \\
\text { [decommissioning of facilities } \\
\text { whose useful life is over ] } \geq 0\end{array}$ & $\begin{array}{l}\text { Minimizing shortages, } \\
\text { operating costs, and the } \\
\text { cost of commissioning } \\
\text { new facilities and } \\
\text { decommissioning } \\
\text { facilities whose useful } \\
\text { life is over. }\end{array}$ & 8 federal districts & $\begin{array}{c}\text { Year / Time } \\
\text { horizon }(5-10 \\
\text { years })\end{array}$ \\
\hline
\end{tabular}

The final implementation includes a financial module describing investment costs for reconstruction, modernization of existing facilities, decommissioning of obsolete equipment, and new capacity additions at energy industry facilities. The model also features the account of the dynamics of development, which allowed to trace such features of the multi-step process of development of the FEC as:

- the commissioning of new production facilities;

- dismantling and preservation of old facilities,

- reconstruction of facilities with changes in the process flow [25].

\subsection{Final summary of models}

Table 1 summarizes information on all of the above models. The analysis revealed that all modifications are a refinement and extension of the original "Nadezhost' TEK" model. In this connection, we can conclude that since the creation of the model, the methodology for analyzing energy systems, calculating optimal solutions, and assessing the level of energy security has remained unchanged, and, as a consequence, has become outdated given the developments in information and computer technology.

The latest modification of the "REKS" model is aggregated and fails to take into account the specifics of many energy processes, in particular, this applies to the electric power subsystem. The linearization of nonlinear elements and the aggregation of power plants and consumers significantly affect the accuracy of the final results. Also, the existing model fails to take into account trends and patterns of modern energy industry development, such as renewable energy, energy storage, and the adoption of digital technology.

In connection with the above, the purpose of further work is to form a new methodology for creating a model of the fuel and energy complex to assess the level of energy security while taking into account current trends in energy industry development, based on the accumulated experience in modeling the FEC.

\section{Methodological aspects of the model being developed}

In the model being developed, it is planned to form a certain territorial structure. This structure will contain the territory of the country while distinguishing individual autonomous republics, krais, and regions, each of which will be a separate aggregated energy area. Cities, neighborhood units, large enterprises, or households can be considered as energy areas for the purposes of the calculation of individual administrative divisions of the Russian Federation. Each level of territorial modeling will provide for aggregation of electric power consumers, grid structures, as well as generating units. At the same time, if necessary, it will be possible to present all elements in detail, including energy storage systems and RES.

The model is planned to implement the possibility of scaling both by time interval and by administrative division. When scaled by time interval, the model will perform various functions: from short-term day-ahead planning to the analysis of future development to 2050 . Territorial scaling will enable us to consider energy systems of different extents: from the energy system of a city with the possibility of treating large buildings individually to the energy system of the country. 


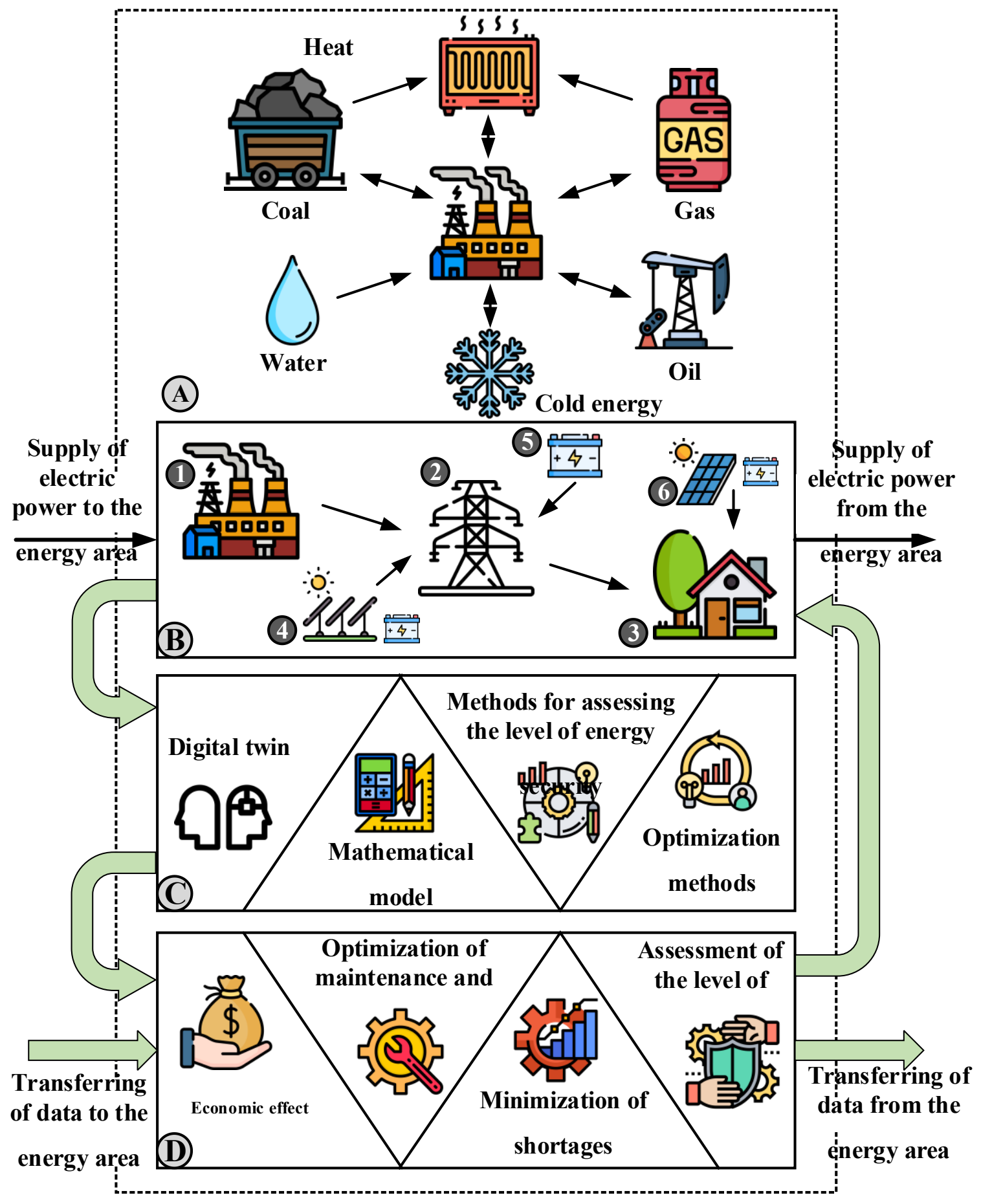

Fig. 1. Structure of the energy area as part of a unified model

In the model being developed, energy areas can be represented by a multi-agent structure. As can be seen from the diagram in Fig. 1, different energy areas can exchange electricity, gas, coal, and oil products, as well as data on the modes of operation of equipment and its technical condition.

The entire model is divided into seven interconnected subsystems: oil, gas, coal, electricity, heat, water, and cold energy. Different energy areas may omit one or another subsystem or its component part (source, consumer).

As can be seen from block "A" in Figure 1, all subsystems are connected to the electric power system via a one-way or two-way link. For example, an energy area has a gas source and a gas-fired CHP plant. When there is an emergency in the gas trunk line, the gas supply to the power plant is reduced, due to this the power generation is reduced, hence a sufficient amount of power fails to be supplied to the compressor stations, and the gas pressure is reduced (Fig. 2). This interdependence of the two subsystems can lead to increased accident severity.

Block "B" outlines the electric power subsystem, which may include electricity generation (1) - power plants (CPP, CHPP, NPP, HPP), transmission lines (2) of different voltages, consumers (3), power plants running on renewable energy sources (4) with the possibility of using 
storage units (5), as well as microgeneration (6). Let us consider them in more detail:

(1) All conventional power plants in the model are divided into five types: CHPP (gas, coal), CPP (gas, coal), HPP, and NPP. For CHPPs and CPPs, we perform unit-by-unit modeling, which distinguishes four types of turbines: condensing, cogeneration, cogeneration with steam extraction for needs of production, and turbines with back-pressure. All other sub-types of turbines are distributed among the four above types according to Table 2 .

(2) The model includes only backbone and inter-system transmission lines (with voltage generally above $110 \mathrm{kV}$ ), which connect the individual energy areas into a common energy system.

(3) Consumers for each energy area can be modeled both separately or in an aggregated way without dividing them into individual categories. The consumer load curve is set with respect to power.

Renewable energy sources are divided into three types: solar power plants (SPPs), wind power plants (WPPs), and small hydroelectric power plants (sHPPs). When modeling RES, a probability distribution is used for random values of the supply of plants with primary energy resources, which allows us to take into account weather and climatic conditions.

Energy storage systems can be installed at various points in the grid, such as at a power plant or at the customer's premises. All the variety of storage types will be aggregated using four parameters: charge rate, discharge rate, capacity, and energy conversion losses, and will also take into account the basic specifics of operation for different types of storage: lithium-ion, lead-acid, pumped, power-to-gas, gravity, etc.

(6) Microgeneration in distribution grids is modeled in an aggregated way by type for the entire energy area. The model considers it as a power plant running on renewable energy sources while taking into account its stochastic nature.

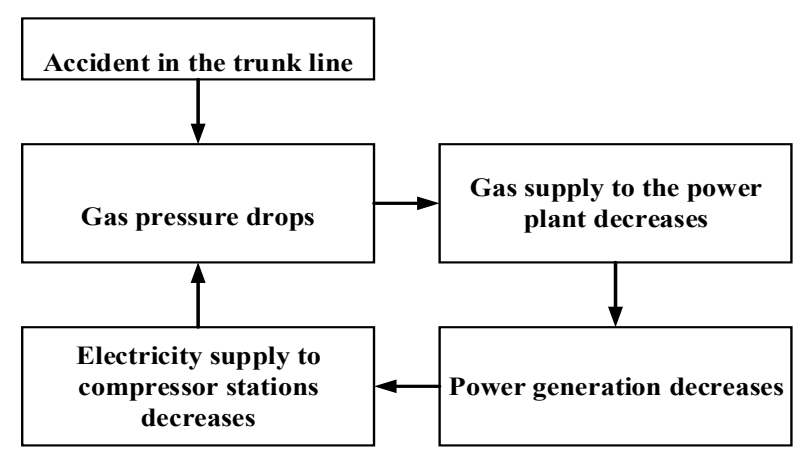

Fig. 2. Link between the gas and electricity subsystems

The final balance is calculated by power and by electricity. The obtained power flows, as well as the data on the required amount of fuel, can be used to optimize the electric power supply in order to minimize costs and maximize profits.

Block "C" is a set of tools employed by the model to make projections, plans, and assessments of the level of energy security. To form a mathematical model we will use typical characteristics of the equipment, its nameplate data, and summaries of its operation. Accumulated historic data on fuel reserves, generation, consumption, and weather and climatic conditions from previous years will be used to plan the operation of the energy system, which is necessary to generate big data for the most wellthought-out forecasting (as in the "digital twin" technology).

Table 2. Types of turbines

\begin{tabular}{|c|c|c|}
\hline $\begin{array}{l}\text { Turbine } \\
\text { type }\end{array}$ & Explanation & $\begin{array}{l}\text { Nominal } \\
\text { type }\end{array}$ \\
\hline PTR & $\begin{array}{l}\text { An extraction turbine, without a } \\
\text { condenser, turbine exhaust is } \\
\text { combined with the lower heat } \\
\text { extraction chamber: it is designed to } \\
\text { maximize the heat extraction } \\
\text { capacity of the turbine. }\end{array}$ & $\mathrm{T}$ \\
\hline KT & $\begin{array}{l}\text { The turbine is the condensing } \\
\text { counterpart of the corresponding } \\
\text { steam turbine of type } \mathrm{T} \text {. }\end{array}$ & $\mathrm{K}(\mathrm{T} ?)$ \\
\hline $\mathrm{P}$ & $\begin{array}{l}\text { Extraction turbines with steam } \\
\text { extraction for production needs. }\end{array}$ & \\
\hline PR & $\begin{array}{l}\text { Extraction turbines with back- } \\
\text { pressure and with steam extraction } \\
\text { for production needs. }\end{array}$ & \\
\hline TR & $\begin{array}{l}\text { Extraction turbines with back- } \\
\text { pressure and with steam extraction } \\
\text { for heating needs. }\end{array}$ & \\
\hline $\mathrm{TP}$ & $\begin{array}{l}\text { Modification of turbines of type T, } \\
\text { made of two cylinders, has } \\
\text { simplified regeneration system } \\
\text { (lacking one high-pressure heater } \\
\text { and one low-pressure heater), there } \\
\text { is one condenser instead of two, } \\
\text { cooling water flow rate is reduced. }\end{array}$ & \\
\hline
\end{tabular}

Block "D" is the output data of the model operation. The latter serves as the basis for the planning and control of energy system operation modes. The data include the results of the assessment of the level of energy security.

It is also worth noting that, due to existing trends in the development of the fuel and energy complex, there is a need to model the information and communication subsystem, which includes digital systems of monitoring, diagnostics, intelligent control, and decision support (or predictive analysis). Thus, when modeling this subsystem, the model becomes a cyber-physical twin of the fuel and energy complex, which will allow one to analyze both "bottlenecks" of equipment and cross-system links and vulnerabilities of the information and communication system to cyber-attacks.

\section{Conclusions}

Research into energy security is a priority task for planning of the development of interconnected operation of energy systems. The approach to modeling modern energy sectors proposed in the study will enable a higher quality of research into energy security if compared against its current level. It will also be instrumental in making both short-term and long-term projections of the FEC operation and identifying bottlenecks, along with solving other problems. 
The literature review attests to the fact that most of the studies model a single node of the fuel and energy complex, i.e., is an energy hub of the multi-energy system, in order to optimize the cost of energy production. We have analyzed the mathematical models of the fuel and energy complex that were designed for studies of energy security and developed at the Melentiev SEI, SB RAS. We provide evidence that the development of models occurred gradually and each subsequent model was an improved version of the previous one.

Based on the analysis of existing mathematical models of fuel and energy complexes, a methodology for their modeling was outlined while taking into account the trends and development patterns of the modern energy industry. Modeling in today's environment should take into account the following:

- nonlinear dependencies of the parameters of the elements of energy systems, allowing for a more accurate capturing of process flows,

- probability distributions for random variables that will facilitate factoring in of the stochastic nature of renewable energy sources,

- individual units of power plants, which will expand the limits of control over heat and power generation,

- energy storage systems that allow for the control over load curves and provide the required power redundancy,

- digital technologies, the adoption of which will directly affect the level of energy security of the country.

\section{References}

1. M. Mohammadi, Y. Noorollahi, B. Mohammadiivatloo, M. Hosseinzadeh, H. Yousefi, S.T. Khorasani. Optimal management of energy hubs and smart energy hubs - a review.Renew Sustain Energy Rev, 89 (2018), pp. 33-50

2. Yong, W., Wang, J., Lu, Z., Yang, F., Zhang, Z., Wei, J., Wang, J. Day-ahead dispatch of multi-energy system considering operating conditions of multienergy coupling equipment. Energy Reports, Volume 7, April 2021

3. Zhou, N., Xie, D., Gu, C., Li, G., Zhang, L., Lou, Z., Chen, Y., Zhang, Y., Chen, A. Coordinated planning of multi-area multi-energy systems by a novel routing algorithm based on random scenarios. International Journal of Electrical Power and Energy Systems, Volume 131, October 2021

4. Zhang, K., Zhou, B., Li, C., Voropai, N., Li, J., Huang, W., Wang, T. Dynamic modeling and coordinated multi-energy management for a sustainable biogas-dominated energy hub. Energy, Volume 220, 1 April 2021

5. Zhang, Y., Hou, H., Huang, J., Zhang, Q., Tang, A., Zhu, S. An optimal subsidy scheduling strategy for electric vehicles in multi-energy systems. Energy Reports, Volume 7, April 2021

6. Chen, L., Xu, Q., Yang, Y., Song, J. Optimal energy management of smart building for peak shaving considering multi-energy flexibility measures. Energy and Buildings, Volume 241, 15 June 2021
7. Gargari, M.Z., Hagh, M.T., Zadeh, S.G. Preventive maintenance scheduling of multi energy microgrid to enhance the resiliency of system. Energy, Volume 221, 15 April 2021

8. Bao, S., Yang, Z., Yu, J. Decomposition and analysis of marginal prices in multi-energy systems. Energy, Volume 221, 15 April 2021

9. Yu. Cao, L. Wang, Sh. Jiang, W. Yang, M. Zeng, X. Guo. Optimal operation of cold-heat-electricity multi-energy collaborative system based on price demand response. Global Energy Interconnection Volume 3, Issue 5, October 2020, Pages 430-441

10. Bahmani, R., Karimi, H., Jadid, S. Cooperative energy management of multi-energy hub systems considering demand response programs and ice storage. International Journal of Electrical Power and Energy Systems, Volume 130, September 2021

11. Rahmatian, M.R., Shamim, A.G., Bahramara, S. Optimal operation of the energy hubs in the islanded multi-carrier energy system using Cournot model. Applied Thermal Engineering, Volume 191, 5 June 2021

12. Chen, H., Zhang, Y., Zhang, R., Lin, C., Jiang, T., Li, $\mathrm{X}$. Privacy-preserving distributed optimal scheduling of regional integrated energy system considering different heating modes of buildings. Energy Conversion and Management, Volume 237, 1 June 2021

13. Luo, F., Shao, J., Jiao, Z., Zhang, T. Research on optimal allocation strategy of multiple energy storage in regional integrated energy system based on operation benefit increment. International Journal of Electrical Power and Energy Systems, Volume 125, February 2021

14. A. Turk, Q. Wu, M. Zhang. Model predictive control based real-time scheduling for balancing multiple uncertainties in integrated energy system with powerto-x. International Journal of Electrical Power \& Energy Systems. Volume 130, September 2021, 107015

15. Ding, Y., Xu, Q., Xia, Y., Zhao, J., Yuan, X., Yin, J. Optimal dispatching strategy for user-side integrated energy system considering multiservice of energy storage. International Journal of Electrical Power and Energy Systems, Volume 129, July 2021

16. Yang, X., Chen, Z., Huang, X., Li, R., Xu, S., Yang, C. Robust capacity optimization methods for integrated energy systems considering demand response and thermal comfort. Energy, Volume 221, 15 April 2021

17. Li, Y., Wang, C., Li, G., Chen, C. Optimal scheduling of integrated demand response-enabled integrated energy systems with uncertain renewable generations: A Stackelberg game approach. Energy Conversion and Management, Volume 235, 1 May 2021

18. Wang, H., Zhang, C., Li, K., Ma, X. Game theorybased multi-agent capacity optimization for integrated energy systems with compressed air energy storage. Energy, Volume 221, 15 April 2021

19. Senkel, A., Bode, C., Schmitz, G. Quantification of the resilience of integrated energy systems using 
dynamic simulation. Reliability Engineering and System Safety, Volume 209, May 2021

20. Ding, Y., Xu, Q., Yang, B. Optimal configuration of hybrid energy storage in integrated energy system. Energy Reports, Volume 6, December 2020

21. Methods of forecasting and analysis of fuel supply system efficiency / Zorkaltsev V.I. - Moscow: Nauka, 1988. - 144 p. (in Russian)

22. Reliability of energy systems and their equipment / Under the general editorship of Yu. N. Rudenko. Moscow: Energoatomizdat, 1994. - 480 p. (in Russian)

23. Antonov G.N., Cherkesov G.P., Krivorutsky L.D. et al. Methods and models for studying the survivability of energy systems. Novosibirsk: Nauka, 1990. 285 p. (In Russian)

24. Hierarchical modeling of energy systems / ed. by N.I. Voropai, V.A. Stennikov. Novosibirsk: "Geo" Academic Publishing House, 2020. 314 p. ISBN (print): 978-5-6043021-94. DOI: 10.21782/B978-56043021-9-4 (in Russian)

25. Krupenev D.S., Pyatkova N.I., Senderov S.M., Boyarkin D.A. Methodological aspects of modeling the interconnected operation of FEC industries in the study of energy security in today's environment. ENERGY-21: Sustainable Development \& Smart Management, 2020 (in Russian) 